01
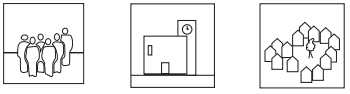

\title{
THE PLACE AND SPACE OF POWER
}

\section{Mess, Uncertainty and Change over Time}

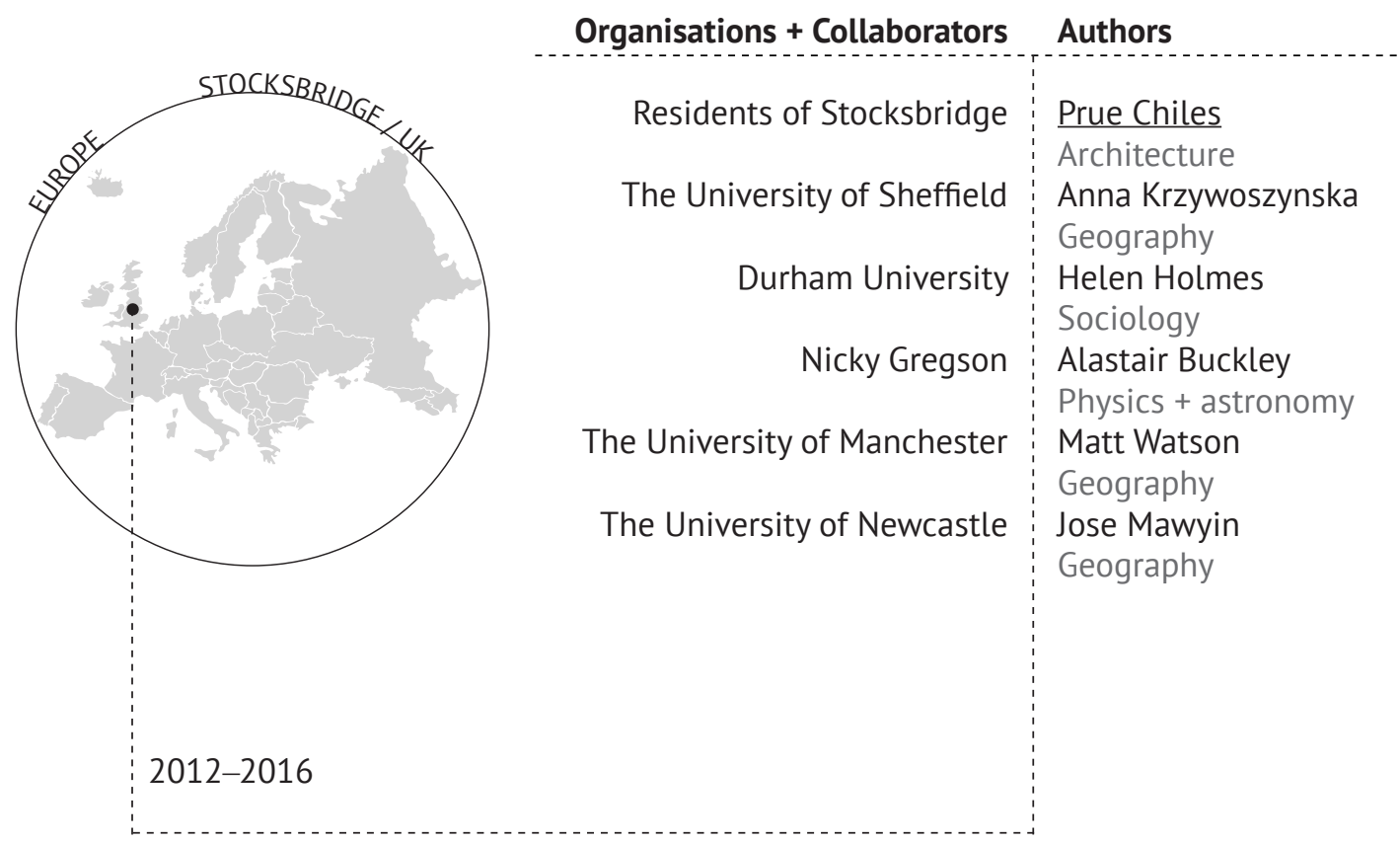

\section{Introduction}

This chapter discusses how a collaborative new-energy project in the industrial town of Stocksbridge, South Yorkshire, enabled us to construct our working definition of trans-disciplinarity. Through the methods of research and the curation of conflicting communities of knowledge and ways of doing, we built on opportunities emerging to create the potential for long-term change. At the outset, this was intended as a participatory "citizen science" project, working with residents on new solar technologies. However, the project became a wider concern with ambitious plans for a sustainable energy future for the town, local energy production, and potential neighbourhood projects such as the refurbishment of a community building into a "green" exemplar.

The four-year project was an extensive collaboration between university participants across a number of disciplines and universities, and a self-selecting public in Stocksbridge. Working through carefully structured participatory events, exhibitions and workshops, each stage of the project allowed us to develop a socially-orientated learning process (uncertain and messy, but in which the 
community of residents began to provide the direction of travel) in order to create meaningful change. It tried to be a genuinely reciprocal project, combining local knowledge, academic knowledge, practice knowledge and "designerly" ways of knowing, to benefit both the community and the university. The transformative action we desired and the consequent shift in power that emerged, came from the tools and skills we deployed and the care and collaboration we developed over time.

\section{The Project, the People and the Place}

"Urban sustainability can be established through community activation, as urban structures exist by the grace of urban rituals and interaction."1

The debate on the production of renewable energy with the involvement of the neighbourhoods and publics concerned, most agree, can lead to more sustainable urban futures. This is of global concern. How it is achieved is more uncertain. The idea for a research project to address this came from a physicist, Al Buckley, an academic with an industry background and a motivation to develop inventive solar solutions. He set about gathering a group of collaboratively minded academics at the University of Sheffield and elsewhere with the aim to co-produce new knowledge leading to new applications for local energy provision in urban environments. An application to the UK Engineering and Physical Sciences Research Council (EPSRC) was successful and a four-year funded project became a reality.

"We wanted to make solar energy relevant to the way we live as individuals, as families, and as communities and work on how we can change the way we think about and act on energy issues. Solar power technology is unique amongst renewable energy solutions as it offers an energy generation capability for individual homes, and opens the possibility of a new, decentralised energy paradigm."

To achieve more locally relevant energy solutions, the academic team was keen to involve energy users as knowledge partners. The project aimed to be critically informed by involving 'lay publics' in science and technology debates as "uncertified" experts (Lane et al., 2011), "to produce mutual learning between academics and public stakeholders; a space of 'science for' but also 'science with society" (Scholz, 2011: 401).

Over the four years the project has been successful in a number of ways and less successful in others. Most notable, we felt, was the way we, over a relatively long period of time, worked closely with the local community of Stocksbridge to develop potential future community energy scenarios. Also, along with academic learning in the fields of energy planning and policy and science and technology studies, a local "Stocksbridge Energy Group" has been established, made up of people passionate about investigating renewable energy sources for the town - including a hydroelectric scheme, the use of geothermal energy from disused mines around the valley, and solar photovoltaics. On a more immediate and practical front, after the project had finished there were plans to improve the energy efficiency of various community buildings. Some of the more ambitious plans for Stocksbridge, however, remain in the pipeline.

Key aspects of this diverse research project, completed in 2017, have already been published - including how the presence of an ethnographer, ${ }^{3}$ embedded in the project throughout, enabled reflexivity within the interdisciplinary research process. As the project was coming to a close we also published a toolkit for interdisciplinary working at every stage of a project. Every discipline has its limits 
and understanding this and placing interdisciplinarity at the core of our work together foregrounded the importance of both disciplinary experiential knowledge and the "spillover" effects ${ }^{4}$ that our different working processes created. These included, for example, a language barrier caused by a conceptual and disciplinary understanding of words - our own private professional languages - that led to misunderstandings. Aside from the more scientific papers, we have also published on the different aspects of the collaboration with the people of Stocksbridge - how we "created forms of engagement that simultaneously address futures as lived, and futures as open. This means taking responsibility for the performative effects of our methodologies, and dealing with the reality of politics and power in participation processes."

There are still many questions to be asked about a project of this complexity and involving so many people, but one early "sticking point" was the many different approaches there were in moving towards a new understanding of the issues of energy generation. These different communities of knowledge ranged from pure science and engineering responses to applied technology, to a community actively developing principles of local energy production as part of their everyday lives. So, during the first two years of the project visions for a future local energy system, local values, aspirations and desires around energy became the central inquiry. It was during this "messy" time that slowly but surely, during the workshops and events, the community agendas took precedence and the shape and direction of the project changed as the balance of power shifted and developed. This chapter looks specifically at the communication tools and processes we devised that facilitated this change in power relationships.

\section{A Place of Power, Energy and Industry - Why Stocksbridge? What Is il Like? Why History Mattered?}

We chose to work in the town of Stocksbridge for a number of reasons. We had had an introduction to the town as a group of University of Sheffield Masters Architecture Students were doing final year thesis design projects based there. It is an interesting edge place, a town of heavy industry with a fascinating history and heritage and, because of this, a diverse population and demographic make-up. It is on the edge of the Peak District National Park and 17 kilometres from the centre of the city of Sheffield. Its location in a deep valley cut by river Don which flows into the city centre of Sheffield, and overshadowed by the Underbank reservoir and dam, have meant that water has always been important in its development. The town's history is all about power, water, energy and industry. Its industrial history started with a cotton fulling mill in the early 18th century which was transformed into an early steel wire mill in 1842 by Samuel Fox. Fox became famous for the invention of the paragon umbrella frame, used all over the world. Stocksbridge is therefore the very embodiment of an early Northern industrial powerhouse, now lessened and compromised but still producing and with huge resources. Stocksbridge plays a large part in the history of the innovative Sheffield steel industry. During our time working with residents in Stocksbridge the plant nearly closed after 160 years but at the last minute found a new owner and high-grade steel is still being manufactured there. However, huge job losses at the beginning of 2020 have put steel production in Stocksbridge under threat again.

Stocksbridge has its own Town Council but would like to be still more independent - recently there has been a sense of political disempowerment and a dissatisfaction with Sheffield City Council. Among other cuts Sheffield City Council closed the town's leisure centre and swimming pool, with the nearest pool now in the centre of Sheffield. It is not very well connected with the city centre, the bus takes ages and the tram from the city stops $11 \mathrm{~km}$ away at Hillsborough. Young people want to be nearer the city centre. It feels like an edge place. One of the team of residents we worked with 


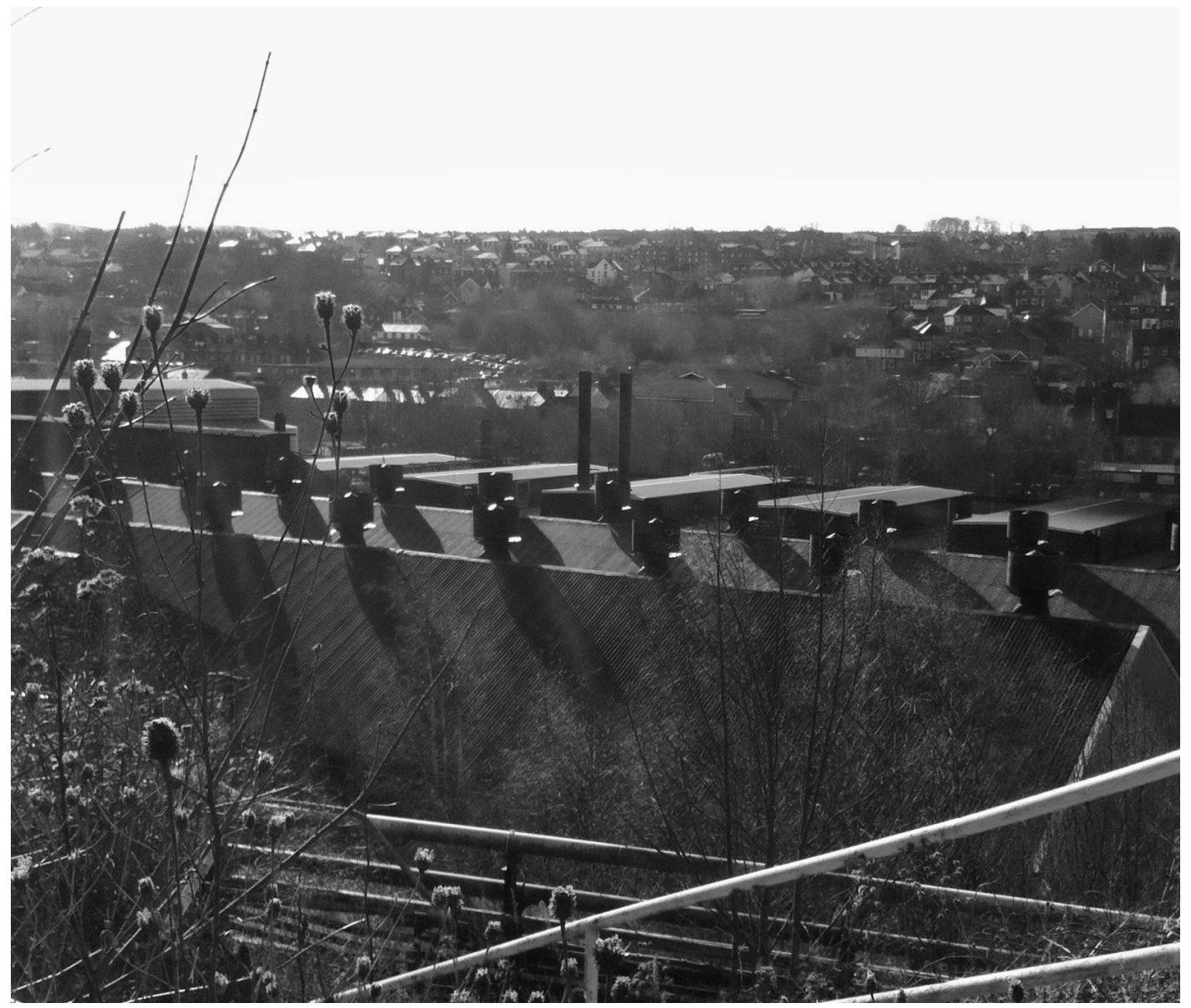

FIGURE II.1.2 A view over Stocksbridge from the steel mills. Photo by Prue Chiles.

commented that "I always feel we are the poor relations of Sheffield, just tagged on at the end." Working with "real" people formed the whole essence of the project, capturing a deep sense of place. The microprojects and different aspects of the town we looked at through energy scenarios, brought together different perspectives from different participants in the project.

\section{The People - Building a Team and Assembling a Public}

The academic members of the team comprised two physicists, two engineers, three geographers, an architect and her Masters' students, a mathematician and an ethnographer. The team took different roles and responsibilities at different periods of the project, and other valuable practitioners and academics joined at particular times. ${ }^{6}$ The Masters Architecture students became a valued part of the project and after their studio projects had finished a small team continued to work with us both to produce drawings and models necessary for visualising and recording our work, and to be part of the team of enablers at the workshops and events. Once the academic team was established, gathering a group of people from Stocksbridge was the next big task. Recent governments in the 
UK have been keen to involve citizens in the future energy provision at neighbourhood and community level; embarking on this project in Stocksbridge we understandably found a huge repository of local knowledge on energy and actively engaged "citizen scientists" exploring geo-thermal energy - as this is an area of abandoned mines.

The catalyst for assembling the project's local participants was an initial exhibition at the Stocksbridge Public Library. We curated and mounted a number of ambitious architectural models, posters, technological artefacts, and games, to generate debate and discussion about potential futures of the local energy system amongst the local visitors. The whole academic team were stationed at different parts of the exhibition to encourage visitors to sign up for the project and to invite them to participate in the first workshop.

The motivations of those who signed up for the project varied but for a number of people the desire was to use local energy production as a means to revitalise Stocksbridge. Stocksbridge resident Andy explained: "what you managed to do was bring a group of like-minded people together with like-minded thinking into a more structured format, lots of people have been talking about renewable energy in Stocksbridge for a long, long time, but not together." We were involved temporarily in sharing their public democratic lives.

This self-assembling disparate group, mainly living, but some working in Stocksbridge, certainly came with their own agendas. Others heard about the project and joined; some quickly lost interest. At one point a contentious political party (UKIP) with a particular agenda and a desire for publicity tried to get us involved in a controversial local cause and of course we had to back off immediately. One or two residents had companies they thought the work might benefit. We tried hard to get the Steel plant, TATA steel, to be involved and nearly succeeded but their economic fragility at the time meant they could not commit to the project. The steel plant was under capacity and a large proportion of the vast valley site was empty industrial space.

Running an academic research project in the community around the theme of energy for a total of four years allowed the project to facilitate new social relationships as well as new forms of social learning. Regular informal meetings helped to embed and explain any issues dealt with in the more formally-organised workshops. The community then began to trust us and know we meant business - and we began to know they meant business. The ethnographer spent much of her time navigating the many different desires, agendas and understandings from the academic team, and in "putting" the public and the academics together. The two full time research associates, a physicist and a geographer, spent a good deal of their time every week travelling, by bus, the 17 kilometres from Sheffield to Stocksbridge turning up at a specified time at the local café for the drop-ins. The full-time academics helped run the workshops and exhibitions with the research associates. Some members of the team were more suited to staying "within the academy" while others were keen to get stuck in with the residents and the events. The whole was greater than the sum of these parts!

All of us, academics and residents alike, embarked on the project feeling slightly uncomfortable in different ways, all feeling lacking in skills and with a touch of the imposter syndrome. Within the academic team too there were varied "agendas" - for the physicists and engineers, a more experimental and data-driven set of results; for the architects, the sustainable agendas of local energy production through relevant action-research and research-led teaching; for the geographers, understanding processes of energy production, building social capital and so on. For the Masters students and for the academics, developing our skills in participation, in listening, was important, and the Masters students also benefitted from the opportunity to use their design, drawing and model-making skills working with publics. Of course, many of our interests overlapped and 
coincided. The Architecture students came to many of the meetings and presented their own design projects built out of the research and their ideas. Their agency and proactive desire to engage with the people and the place, and their youth, all helped in setting up and contributing to the changing processes of the project.

Sessions or reviews in the university with the academic team on the students' projects helped the former develop their ideas, although at times there was also frustration at different and disciplinary understandings. Al, the Physicist, for example was frustrated at architecture students' reluctance to solve energy calculations accurately - they preferred someone else to do this and for them to apply this to broader problem solving and design decisions. As part of the interdisciplinary understanding of disciplines this was one of the first times we realised we all have our own skills and ways of working.

\section{Building Social Capital - Conditions and Tools to Build the Collaboration and Change the Power Dynamics - Models, their Use and Meaning}

\section{Models, their Use and Meaning}

"Models as objects are a bit ordinary, rooted enough in the everyday to seem familiar, formally intense enough to seem sublime."

At the first exhibition to introduce ourselves in the Public Library at Stockbridge we, the academic team, hoped the architectural models, posters, technological artefacts and games, would provide visual interest and an engagement with the themes and aspirations of the project. We hoped to inspire Stocksbridge residents with the potential project. We understood the power of models to both attract a public and to aid discussion, but were not so aware of their destructive power, their capacity to disrupt and to antagonise the residents. The scaled down truth of a model offers instant totality, a place modelled in tiny but perfect detail and a kind of stark visual reality.

The MArch architecture students had been commissioned and briefed to build two models. One large model to show a "what if' energy future for the whole of Stocksbridge (Fig II.1.1) to understand the scale and extent of the town. Many of the conversations and the sharing of ideas collected standing around a model are about distance and proximity - about someone's house in relation to their colleagues'. We found it was a great way to introduce, for example, just how close parks were to them, the relationship of their familiar domain to one they have never visited. There is a shift in power dynamics when communities, or the citizen generally, wanting to think about new buildings, suddenly feel they have an understanding of space or place. They can not only see what they need but they can give some impression of the space they inhabit or would like

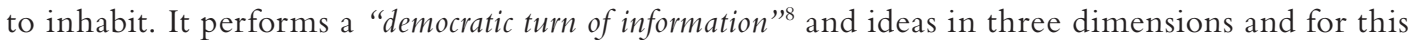
reason is probably the best, and most intuitive, way to construct a plan of what to do next.

The model mainly presented solar technologies, where and how they could be placed. However, for discussion, they had also situated thirty or so wind turbines on the hill above the town. Most of the houses would look out at these. Understandably this had an immediate impact and created criticism and debate on the destructive effect the one (existing) solitary wind turbine had on the neighbourhood. It was noisy and thought to produce disruptive waves that created headaches and dizziness if you were nearby. The thought of thirty turbines was more than some could bear.

We hadn't successfully explained the status of the model, neither had we really thought through the ramifications of wind power. However, getting their point across about wind power, making us 


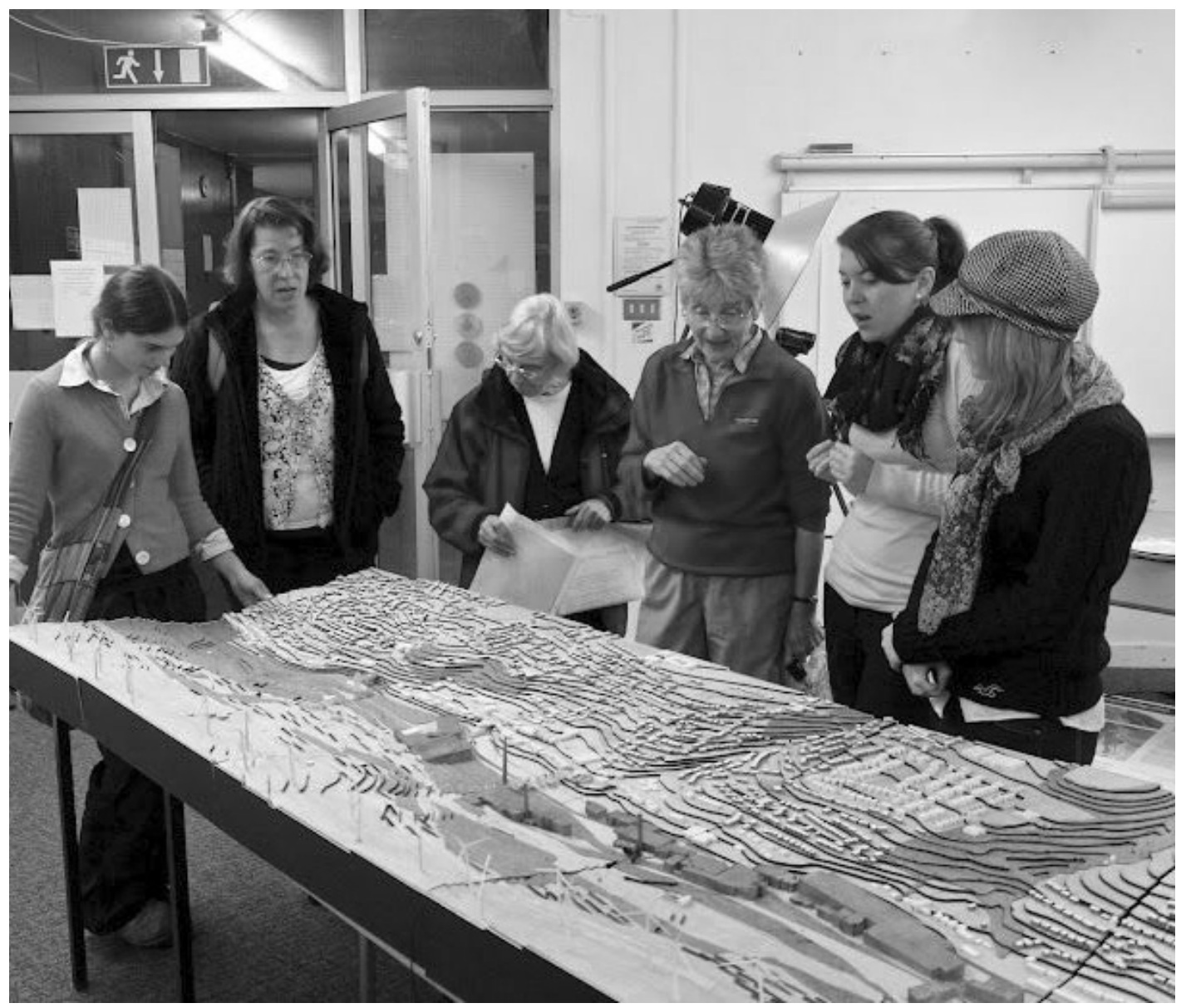

FIGURE II.1.3 A difficult discussion on wind power around the model. Photo by Prue Chiles.

see their worry, and seeing us sympathise and extend the discussion was an important step in our relationship.

At a smaller scale a ply model of a house, at a scale of 1.50 with a lot of detail and the feel of a sophisticated doll's house, complete with photovoltaic panels and opening parts, was only looked at and not really played with by children. It looked and felt too finished, too perfect; even though we wanted children and adults to touch and play with the model, it looked out of bounds. We presented this too early in the process. It was far less successful than the model of the whole of Stocksbridge. Models of terrain and of topography allow the viewer to zoom in and out to see a "god's eye view" of their immediate area. The power of models is in their scale, in this miniature life of their own, they become a realisation of what architecture or a place promises, yet can never actually attain itself.

They can represent or symbolise the structures of power and be a focus for change and development or other practices. Models are a powerful tool. 


\section{Working with Scenarios from “an Empty Future” - to a Place-Based Scenarios}

During the project we held numerous whole-team meetings, planning events, seven large public workshops, sub-meetings on specific projects, three exhibitions and conference presentations, in academic circles and usually collaboratively with residents. This amounted to approximately one event every month over the main intensive period of collaboration of two and a half years. After the first exhibition in the library, a substantial group of about 25 people signed up to be part of the project and turned up for the first workshop in a community centre in Stocksbridge. Already before the first workshop, the potential benefits of the project's presence in the town were discussed at the Stocksbridge Community Forum, where a new Community Energy Group was formed with the intention of generating renewable energy projects for the benefit of the Stocksbridge community.

The first couple of workshops were tentative - we were feeling our way. The first half an hour was arranged as a large circle before breaking into round-table working groups of 5-7 looking at different themes within solar energy. Like all well-planned events the organisation was huge - lifts for older members without cars, catering, notices etc. were all put in place. The key scenario for the first workshop meeting was about the solar technologies and about the future of solar energy. The participants had lengthy workbooks prepared for them by the researchers, full of really interesting material and huge amounts of information to absorb and discuss - a veritable Open University offering, slightly intimidating and, we realised, much too much work for the community participants to complete. However, these came into their own later when we reported on what we had done and they developed into a useful diary of events and the progress of the project.

"It's as if we are in the business of creating frustrations for ourselves, for the participants, all the time we're just creating very frustrating situations, asking people to do things that are very counter-intuitive, to us and the participants I think" - quoted by one of the academic team in an external interview on the process. ${ }^{9}$

Although some of the discussions were interesting, engaging and fruitful, they were not necessarily relevant to the everyday future of Stocksbridge. An empty future is not a meaningfully liveable one. "the uncertainty associated with the 'blue skies thinking' scenario workshops depend on, becomes an obstacle to generative engagement." ${ }^{10}$ When the participants see themselves as stakeholders in the scenarios, involved in deciding on an alternative way of engaging with the future, "being a public" becomes more valid. We became more and more aware of this through conversations with the participants during the first workshops. We started looking closely at key themes that were emerging for the community and the future of the town. We devised a different approach where everything was related to Stocksbridge, their neighbourhood and place they live.

\section{Co-producing Place-based Scenarios - The Transfer of Information.}

"The process also involves a lot of uncertainty, not just with respect to what kinds of projects the residents may propose, but even whether or not they will even engage. In the light of their experiences so far, the core team has become very open regarding what might happen in the future."11

The rest of the workshops turned to key topics relevant to their approach to energy use in the community and how a different energy future could transform the town. So, the next workshops encouraged residents to join one group they were particularly interested in, approximately six or 


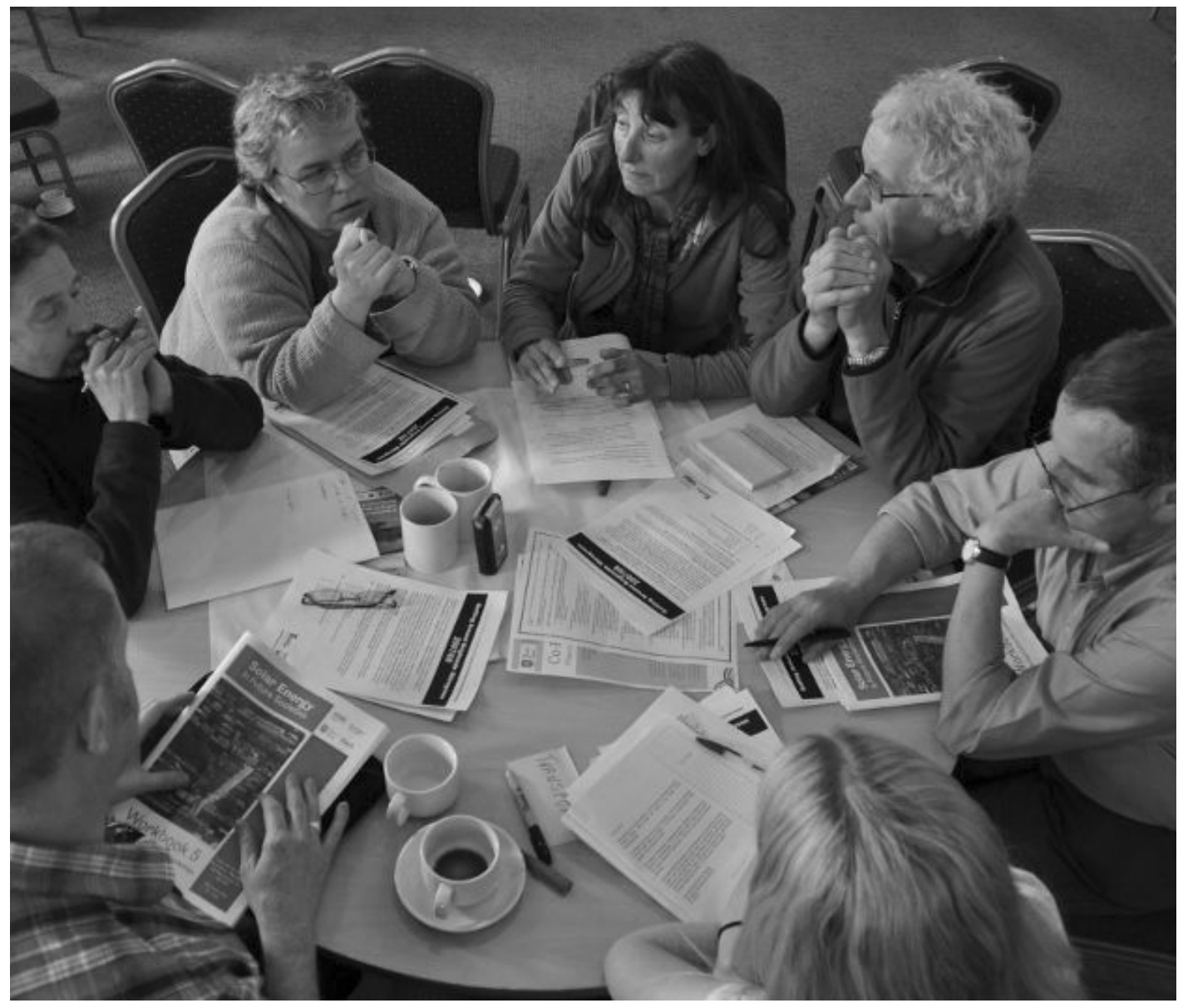

FIGURE II.1.4 Studying the workbooks at a round table discussion. Photo by Prue Chiles.

seven people, including one person from the academic team in each and the process picked up pace. Five core themes coming from the participants, that formed the groups, were:

1. Local Energy Production - investigating the best combinations of technologies for energy generation in Stocksbridge how these could be implemented. A district heating network that could utilise the abandoned underground mine network is one of the options that is being researched in more depth.

2. Transport - this theme collected stories of past transport, talked of health - steep hills and extending the tram from Hillsborough. Resurrecting the train to Sheffield City Centre was a very popular idea. Three people were very interested in electric buses. The transport group linked to the other groups, as any community space that is improved or created will require easy access for all residents of Stocksbridge. In particular, transport linked to the local energy production group as the energy produced could be used as part of a day to day transport system.

3. Sustainable Buildings and Sites - these locations are potential "hubs". More than one could be taken forward as they could offer different functions. For example a monitoring station in the 


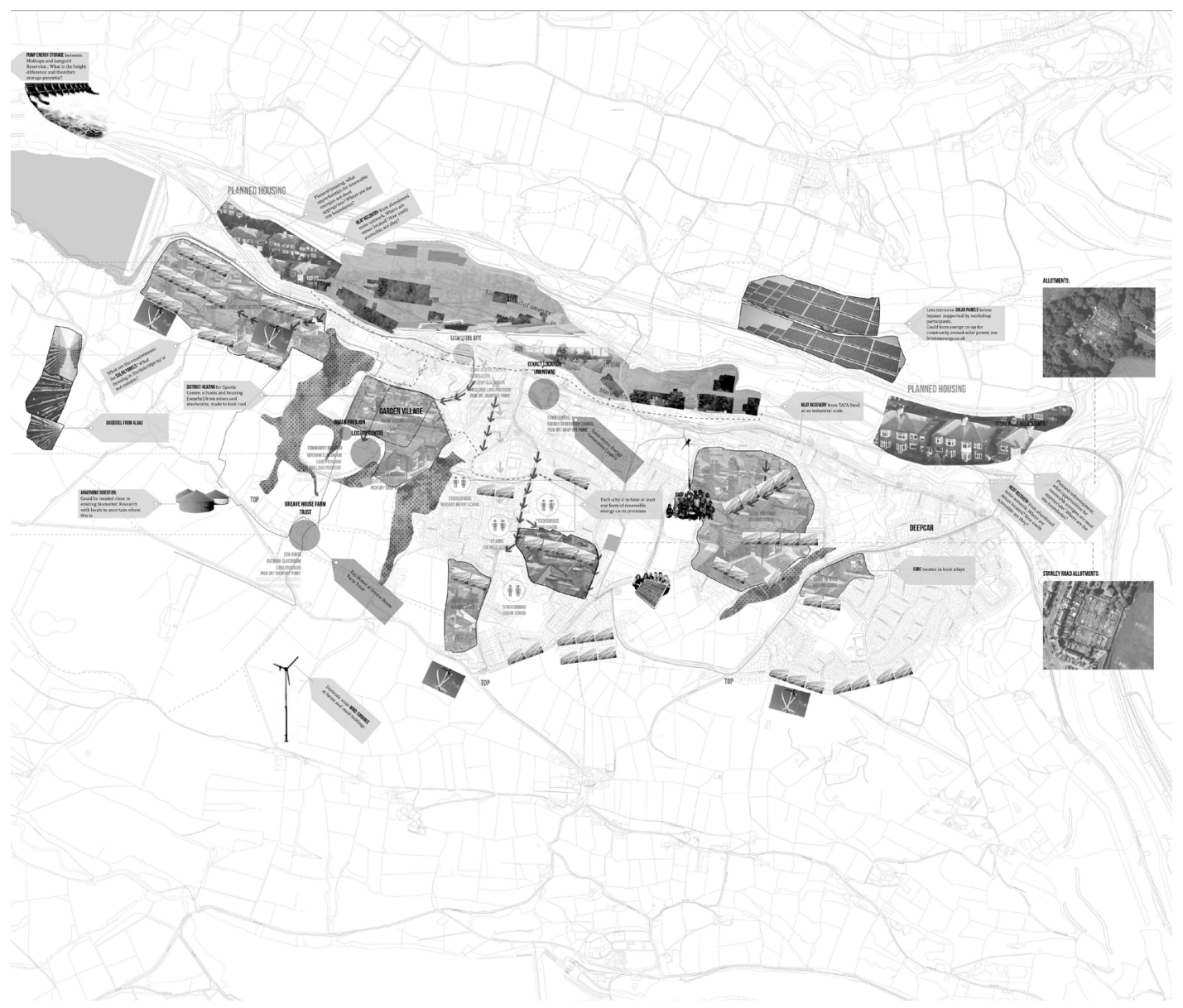

FIGURE II.1.5 The whole vision for an energy future for Stocksbridge, collating projects and possibilities. Authors: Collaged map by the architecture students.

centre could be an object that shoppers walked past day to day, while the Inman Pavilion could be the location for an outdoor education space, dance studio, community centre and "demonstration building." This latterly became the focus of this group. ${ }^{12}$

4. Growing Food and Food Production - this group worked on how they could use the excess heat from Tata Steel, creating possible sites for sustainable food production organised by residents of Stocksbridge. The meals 'hub' could have an education aspect; it would require a sustainable greenhouse; the greenhouse should harvest and store excess heat energy; it will provide a new focal point which will need easy access for residents of Stocksbridge.

5. Education - taking this work into schools we all felt could have real impact - as children are always ahead of parents in sustainable ideas. Two residents, one a teacher, were very keen to collect materials and arrange workshops and to involve the children in some way in the projects spread around the town. This was particularly linked to the sustainable buildings group. 
More than other tools and processes, collaborative visioning, in this case of local energy systems, can enhance social learning and the social capital of communities. In all the groups it was about measuring the achievable with the utopian. Critically reflecting on the process, it was the tension between the "inspiring" and "empowering" role of visions and the situated nature of the visioning processes within broader power landscapes that we had to recognise and respect.

In the groups the relationship between practice and research was also present and discussed in relation to developing tools to work in the project. What we learned here was that it is difficult to understand your roles and your value. Is developing visions enough, should and could we, particularly the architects, do more? Could we be more involved, move from research to a potential tangible outcome? Move from researcher to practitioner? There is always a temptation to break out and do something differently, without explaining why. The reality of modernity is that contingency, uncertainty and lack of control are inevitable conditions we have to face. One of the biggest issues for community projects moving forward is fatigue. Participants are excited and then when they return home nothing moves forward. How can the enabler foster resilience and unlock the energy and confidence required for the individuals and the representative group to continue their empowerment journey?

It struck us in some instances that the transfer of information, sometimes offering something to keep, was our offer of "the gift." ${ }^{13}$ That was the intention of the workbooks and perhaps also the large model, the whole miniature world of Stocksbridge captured - and which we finally gave to the community. Also, the drawings which we exhibited and wrote over collating changes and comments and then finalising. All these were left with the community of residents. The participants were gifting us local knowledge, their time and experience. With the exchange of gifts comes obligations though, combined with an understanding of social conventions.

\section{Drawing the Scenarios - The Role of Drawings}

Developing tools for a collective conversation exchange can take many forms - as with models, drawings and other visual props or in situ graphics, collages, diagrams, maps are all valuable. We used drawings in a number of ways, the most intimate being the creation of sketches with residents, over a table, a shared endeavour, a way to both express yourself and to laugh together, to build confidence and to make collective decisions. It is not easy but things can become more real as you visualise them emerging in front of you. Simple diagrams and maps, pinning down place and scale, were important, measuring distance and seeing possibilities in a different way to a model.

The Architecture students worked with collage for the first collective vision using familiar images and placing them together to suggest ideas and possibilities; to start a discussion. Drawings render the invisible, visible. Drawing with others needs to start simply, something that isn't fixed and can suggest possibilities - not definite changes. "The drawing encourages the gaze to proceed beyond the visible image into an infinity of thought" 14 where something new is encountered. Drawing can help to re-situate neighbourhood discourse beyond its neo-liberal, institutionalized or pure scientific framing, it can allow for the imagination and create confidence but this takes time and patience. A drawing, if it is understandable, can cut through spatial and cultural divides and difference.

The detailed drawings and diagrams for the exhibitions and for explaining the scenarios at the end of the project were a refined and codified transformation of all the collated ideas. Local residents championed each scenario and took responsibility for it, their photographs adorning the drawings and diagrams. 

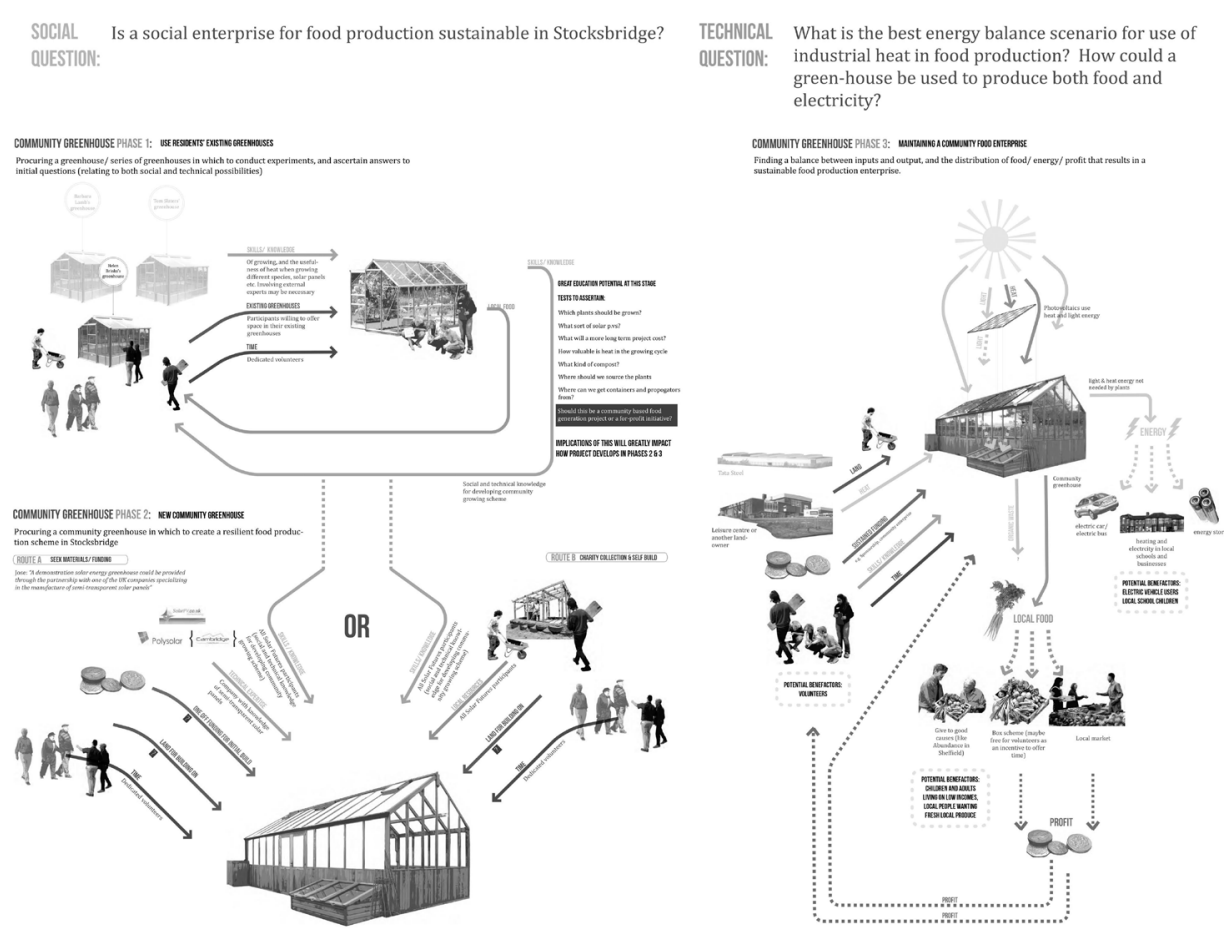

\section{MEALS} green-house be used to produce both food and

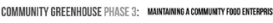

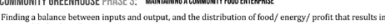
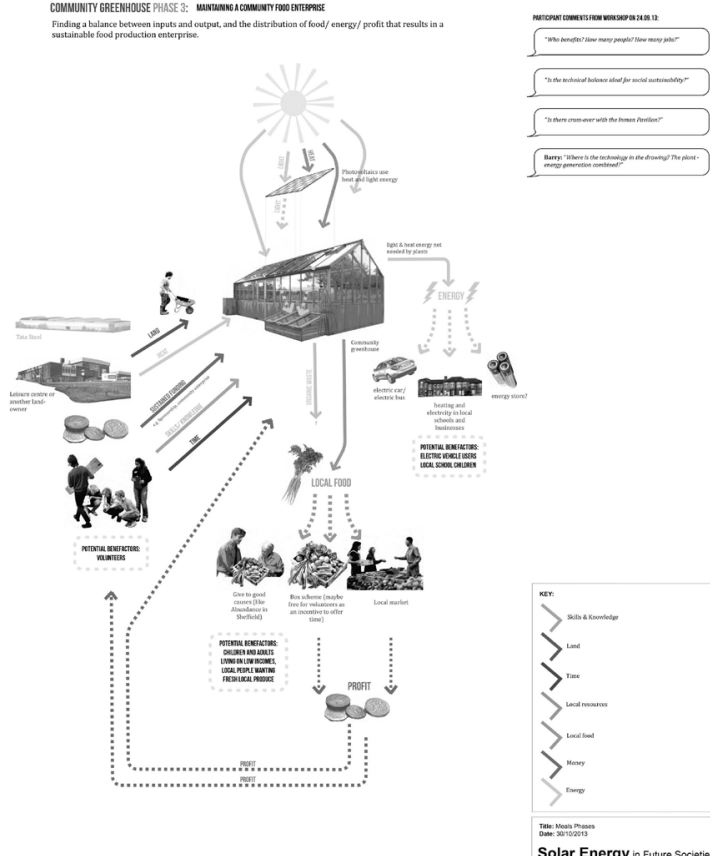

FIGURE II.1.6 Diagram showing the ecology of growing food and food production. Authors: Collaged map by the architecture students.

\section{Values and Principles Emerging}

Some values and principles emerged that were instrumental to the way we worked with our tools and ideas. They were important and enabled the changes and the transfer of power from the academics to the community.

\section{Mess}

The concept of "mess" 15 acknowledges that the project and the process is not linear, that not all that goes on in such research projects can be ironed out and simplified. Rather "mess" exists and should be accepted for what it is. Throughout the life course of the project, serendipity played its part - the things you cannot plan for. Also messy were the elements of a project which occurred outside of the project's traditional boundaries, for instance going for a drink with colleagues and discussing the project. "Mess" is the very stuff of our collaboration and interdisciplinary 
working. It is what defined our project and bound it together. It is through this mess that we recognised the "added value" of our involvement in such collaborative working: the "spill-over" effects from other disciplines which influence the way we research, teach and learn within our own. The real value of the project emerges when more recognition is given to the small spillover effects of the collaboration and the interdisciplinary modes of working, rather than focusing solely on knowledge outputs and impacts. These spillover effects were in relation to our very different teaching practices, project management and research methods, and these can, in turn, then be taken back to our disciplines to move them on.

\section{Time and Care}

A recent turn to "the question of time" is vividly explored in Lisa Baraitser's Enduring Time (2017). She feels that maybe this has something to do with our millennial anxieties about the impact of technologies accelerating time (speed theory). To this we can add the collapse of 20thcentury modernity's belief in our dominance over our future, which becomes more uncertain and unpredictable. The energy debate and the consumption of fossil fuels is at the centre of this uncertainty, and working around this with the Stocksbridge Community there was a palpable feeling that it was "time to do something" in the neighbourhood, that the council were unable to fulfil this future-looking role. There was a certain momentum and pace to the project - the rhythm of time altered throughout and this affected the collaboration. Time and transdisciplinarity are intimately wrapped around each other and became for us a particular concern in a project, where we, as a heterogeneous academic community, were sharing time together with a community of people from Stocksbridge who agreed to work with us. People's generosity with time, whoever they were, needed to be respected as does the contribution of those who are short of time. Care is also positioned centrally in the relationship between interdisciplinarity and transdisciplinarity. Care here is a value, "a practice that takes the form of an affective engagement with others" (Baraitser, 2017, p. 14).

Although Baraitser is often talking about more fundamental and personal issues in her book, she speaks of the temporal tropes of staying, maintaining, repeating, waiting, delaying, preserving, enduring and recalling - all surely core qualities to make collaborative, participatory and transdisciplinary endeavours successful. Time and care together created trust.

\section{Hope}

Finally, we turn to notions of the future and hope in that future. We saw throughout the project the role of hope, which acted as an enabler in developing public involvement, but simultaneously as a source of tension when hopes for the future are confronted with the inescapable uncertainties. The most serious of these is the uncertainty of the steel industry and of employment striking at the very identity of Stocksbridge: the place, its history and its future. Hope is an important part of our deepest desires expressed in our view of the world - hope that the future will be bright, hope that the world will still be here and a better place long after we have left. A number of the participants in the project talked about Stocksbridge as a place for their grandchildren. Ernst Bloch describes hope as "an essential force in everyone's lives, because being strives to fulfill itself by realizing that which is not-yet-being." 16 


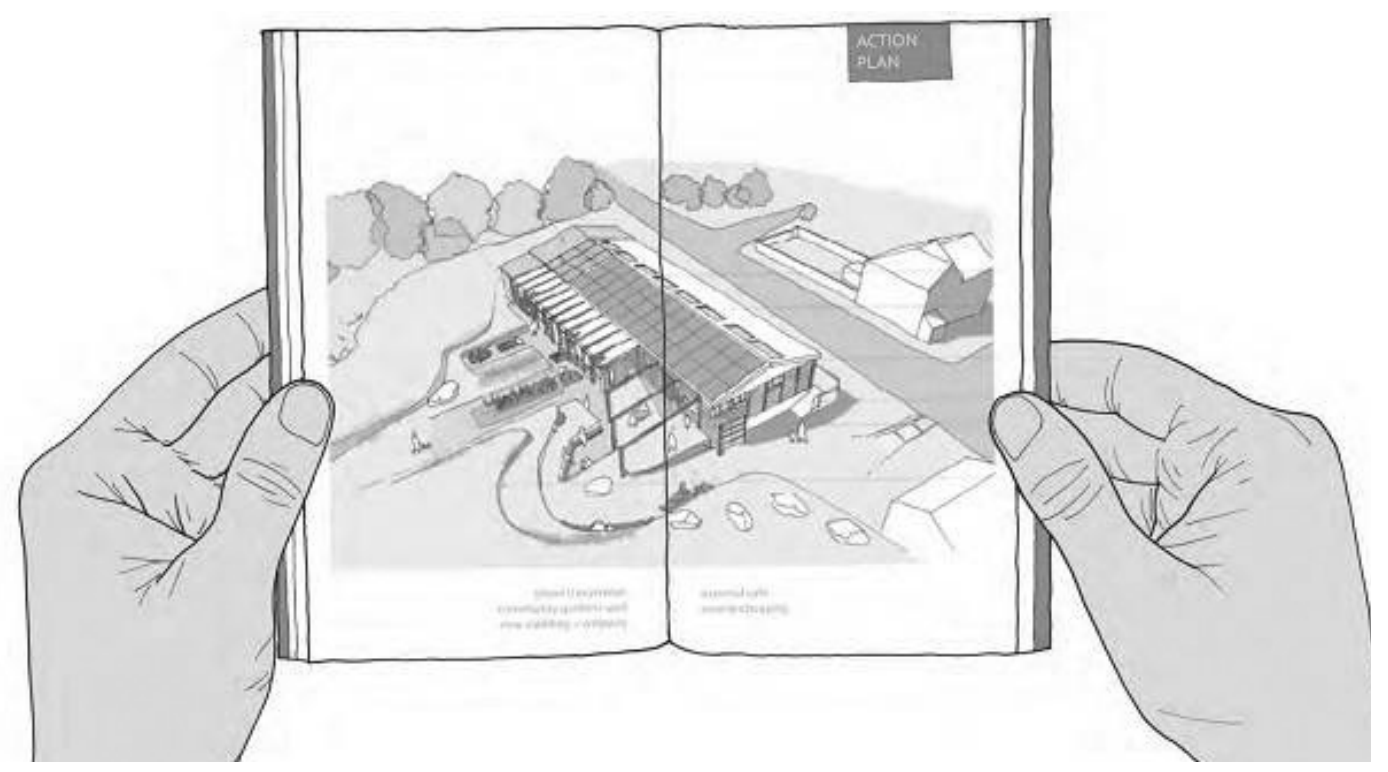

FIGURE II.1.6 The Inman Pavilion as a demonstration building for sustainability and local energy. Photo by Prue Chiles.

\section{Defining Transdisciplinarity - Some Concluding Comments}

This chapter has asked the question of whether working in a transdisciplinary, co-productive way genuinely redistributes power relations through environments, technologies and practices in community economies? It also asked what the relationship between practice and research was in relation to developing tools to work in the project? What are the barriers and opportunities emerging from different and sometimes conflicting communities of knowledge, coming from different disciplines and the complexity of processes and their relationship to each other? These acknowledge that practices must evolve to match the complexity of the issues facing today's big questions. What are the methods to enable successful collaborative and relevant research at the neighbourhood level? Reflecting on the project four years on, our conclusions on a successful transdisciplinary way of working combine using a series of hands-on visual and tactile tools and props that enable conversation and allow decision making and learning in time, deeply rooted in space and place. It also combines different communities of knowledge with research and practice. A successful result of transdisciplinary working is a change and oscillation of the power-structures of the project showing trust, confidence and positive change.

"staying, maintaining, repeating, waiting, delaying, preserving, enduring and recalling."

\section{Acknowledgements}

We would like to thank the whole team involved in the solar energy in future society project and especially all the residents of Stocksbridge, who gave generously of their time and energy. Thanks also to architect and $\mathrm{PhD}$ candidate, Vera Hale, who joined the enabling team. She was unusual in her ability to draw and to discuss, over drawings, with residents. Her PhD explores participation through enabling. 


\section{Notes}

1 Richard Sennett, in his early The Corrosion of Character: the Personal Consequences of Work in the New Capitalism. (Sennett, 1999).

2 One of the academic team as interviewed by Helen Holmes in: Interdisciplinarity in transdisciplinary projects: circulating knowledges, practices and effects (Holmes et al., 2018).

3 Helen Holmes in Interdisciplinarity in Transdisciplinary Projects: Circulating Knowledges, Practices and Effects - and the Interdisciplinary Toolkit (Holmes, 2015). Available at https://www.sheffield.ac.uk/ idtoolkit/about.

4 Ibid, Spillover effects included many small everyday things that changed the course of the project, chance conversations or comments about something found, visiting local sites and finding the unexpected.

5 Anna Krzywoszynska in the Participation Laboratory e-publication: Krzywoszynska, A.D., Watson, M., Buckley, A. et al. (4 more authors) (2018) Opening up the participation laboratory: the co-creation of publics and futures in upstream participation. Science, Technology \& Human Values. ISSN 0162-2439 https://doi.org/10.1177/0162243917752865.

6 Architect and PhD candidate, Vera Hale joined the enabling team.

7 From Mark Morris in Architecture and the Miniature in 2006.

8 Lave, J. W., 1991.

9 From the Protee report - Ruth McNally and Maia Galarraga - A mid-project audit carried out on large EPSRC funded projects.

10 Ibid.

11 Ibid.

12 Developed subsequently in a Live Project: a six week programme with Masters students from the Sheffield School of Architecture. Available at http://www.ssoa.group.shef.ac.uk/.

13 The Gift, a hugely influential concept in ethnography. see Godelier, Maurice (1999) on Marcel Mauss.

14 These ideas are discussed on p. 7 of the Introduction by Marco Frascari From Models to Drawings.

15 Donaldson et al., 2010 on mess and written about extensively in Holmes et al. in 2018.

16 Quoted in Heynan, 1999 p. 119.

17 Baraitser, 2011.

\section{References}

Baraitser, L. (2011). Enduring Time, Bloomsbury.

Frascari, M., Hale, J., Starkey, B. (2007). From Models to Drawings, Routledge.

Godelier, M. (1999). The Enigma of the Gift, Polity Press.

Haber, W. (2013). Review of: Scholz, R. W. (2011). Environmental Literacy in Science and Society. From Knowledge to Decisions. Raumforschung und Raumordnung 71, 69-71. https://doi.org/10.1007/s13147-012-0203-x.

Heynan, H. (1999). Architecture and Modernity: a critique, MIT.

Holmes, H. (2015). The Interdisciplinary Toolkit. https://www.sheffield.ac.uk/idtoolkit/about.

Holmes, H., Buckley A., Chiles P., Krzywoszynska A., Watson M., Gregson N. (2018). Interdisciplinarity in Transdisciplinary Projects: Circulating Knowledges, Practices and Effects. DisP - The Planning Review 54(2), 213. Jenkins, P., \& Forsyth, L. (2009). Architecture, Participation and Society, Routledge.

Krzywoszynska, A., Buckley, A., Birch, H., Watson, M., Chiles, P., Mawyin, J., Holmes, H. \& Gregson, N. (2016). Co-producing Energy Futures: Impacts of Participatory Modelling, Building Research \& Information, 44(7), Co-producing Neighbourhood Resilience - Special Edition, 804-815. DOI:10.1080/09613218.2016.1211838.

Lave, J., \& Wengers, E. (1991). Situated Learning, Legitimate Peripheral Participation, CUP.

Morris, M. (2006). Architecture and the Miniature, Wiley.

Sennett, R. (1999). The Corrosion of Character: the Personal Consequences of Work in the New Capitalism, W. W. Norton \& Company, Inc.

Wilkinson, A., \& Mayer, M. (2014). Collaborative futures: Integrating foresight with design in large scale innovation processes - seeing and seeding the futures of Europe. Journal of Futures Studies, 18(4), 1-26.

Wilsdon, J., \& Willis, R. (2004). See-through Science: Why public engagement needs to move Upstream, Demos. 